\title{
Factors Influencing the Evolution of Electronic Commerce: An Empirical Analysis in a Developed Market Economy
} \section{Inma Rodríguez-Ardura ${ }^{1}$, Antoni Meseguer-Artola ${ }^{2}$ and Jordi Vilaseca-Requena ${ }^{3}$}

Internet Interdisciplinary Institute, Open University of Catalonia (Universitat Oberta de Catalunya, UOC) 1 irodriguez@uoc.edu, 2 ameseguer@uoc.edu, ${ }^{3}$ jvilaseca@uoc.edu

Received 23 October 2007; received in revised form 12 May 2008; accepted 27 May 2008

\begin{abstract}
This paper tries to explain the temporal evolution of electronic commerce in a developed country. For this purpose, we evaluate the contribution of the size of the potential market represented by the community of Internet users to the development of electronic commerce, as well as of other determinant factors. The validation carried out, for the whole Spanish market and over a period of seven years, reveals the existence of a critical threshold of online consumers that, once surpassed, supposes a change in the growth trend of electronic commerce. Likewise, we verify that broadband technology diffusion, the definition of a legal framework of consumer protection, and the design of a value proposition perceived as "secure", also influence the development of electronic commerce. We also confirm the contribution of firms' differentiation strategies to the development of electronic commerce, to the detriment of those based on price leadership. Finally, it seems that possession of a computer is no longer an indicator of access barriers.
\end{abstract}

Key words: Electronic commerce, Adoption, Development, Determinants, Evolution, Internet, Spain 


\section{Introduction}

Since the Internet began to be used in business, both practitioners and academics have been interested in identifying the factors affecting the activities of e-commerce, and understanding how they affect its development or the extent of its use. At present, it is still important to study the e-commerce phenomenon, since it is continuously evolving [11], and generalizable evidence is still lacking.

As a whole, the empirical work undertaken since the mid-1990s, particularly for advanced economies, has identified a large and varied number of determinants of Internet and e-commerce adoption and development (factors to do with the competitive environment, technological and organizational factors, etc.), which has led some authors (such as Fillis et al. [21], and Kim and Galliers [33]) to review them. However, more empirical work is needed to test the choice of these determinants.

Moreover, it is also desirable that the identification and analysis of the determinants of e-commerce take into account the particular characteristics of the competitive environment of each economy or market. The specific determinants affecting e-commerce may be very different depending on the type of competitive environment involved [44]. In fact, specific analyses are required that consider the particular features of e-commerce for the end-consumer markets. Although the potential for development of this type of initiative is extraordinary, particularly in advanced economies, where the majority of consumers has substantial purchasing power and possesses the minimum technological equipment necessary to connect to the Internet, limitations still exist, and these should be identified and analyzed.

At the same time, the study should be longitudinal — contemplating the temporal evolution of the phenomenonrather than cross-sectional.

With the aim of accomplishing these research objectives, we have defined a holistic and theoretically constructed model that identifies factors from the competitive environment (of a developed country) and the firm's value proposition that might affect the evolution of the B2C e-commerce phenomenon over time.

We have structured the present work in five sections, including this short introduction. In Section 2 we review the literature on the adoption and development of e-commerce, and then propose an explanatory model. This will be the starting-point for identifying the variables and obtaining the data to be used to test the previously-defined model, which we undertake in Section 3. Then, in Section 4, we present the results obtained. First, we study the dynamics of the phenomenon under analysis, comparing this with one of its most important determinants: the size of the potential market represented by the community of Internet users. Highlighting the close interdependence between these two variables is the starting-point for validating the explanatory model proposed here, to which we also incorporate other determinants identified in the literature review. Finally, in Section 5 we discuss the findings in order to present the main conclusions of the work and highlight our contribution with respect to the determinants of the evolution of ecommerce.

\section{Determining Factors of B2C e-Commerce}

Few innovations introduced in the field of commercial distribution in the past few decades have as many advantages for both consumers and firms in developed countries as e-commerce on the Internet, a commercial format enabling the purchase and sale of information, goods and services through that communications network. Indeed, the benefits of this commercial format are obvious: it is global, it is capable of interconnecting and interrelating millions of buyers and sellers, it enables marketing communications to become interactive, the business opportunities deriving from its use are very varied, and so on.

Nevertheless, and despite these advantages, the Internet still remains an emerging environment in commercialization, particularly with regard to firms' electronic exchanges with end-consumers (B2C). Unlike electronic exchanges between firms (B2B) - which are favored by the fact that firms can carry out their purchase and supply activities much more efficiently in the virtual environment- B2C e-commerce is more dependent on elements from the end demand, which are often beyond firms' control.

\subsection{Factors relating to firm's competitive environment}

Analyses of e-commerce taking a holistic or integrative prospective do not always consider aspects relating to the end-consumers, despite their importance. This may be justifiable in the case of B2B e-commerce, but even some studies of B2C e-commerce ignore such elements (see, for example [3], [65]). Among the aspects relating to the consumers worth considering, the size of the potential market is particularly important [30], [43], [55]. Indeed, reaching a critical mass of potential customers who are habitual users of the Internet may turn this group of users into a large enough market to become profitable and consequently attractive to firms [32], [45]. This leads us to propose the first hypothesis: 
H1: The size of the potential market on the Internet positively influences the development of e-commerce.

But as well as being conditioned by the potential market, the development of e-commerce may also be influenced by other opportunities and limitations imposed by the competitive environment [33], among which we could highlight those to do with the technological infrastructure, and factors relating to the legal framework within which commercial activity on the Internet takes place [30].

As an application of the Internet, e-commerce depends on information infrastructures and telecommunications for its development. Specifically, Stewart et al. [61] point to the broadband penetration rate as one of the factors best explaining the different levels of e-commerce adoption and development observed in developed countries such as the United States, Canada, United Kingdom, and Australia, where in any case the conventional Internet access infrastructure is widely available [19].

Indeed, the penetration of low-cost broadband in the population allows companies to provide a better service to their customers, since it allows them to develop websites with personalization mechanisms [2] and personal interaction with the customer services area, or other personnel from the organization [41], and to incorporate various differentiating hypermedia elements [50]. Thus, many authors have found evidence of the positive effect of designs that are advanced and suited to the audience on the results of e-commerce operations ([18], [38], [40], among others).

On the other hand, the adoption and development of e-commerce also depends on the degree of involvement of the public authorities in developing a legal framework and a set of policies that favor its development [21], [22], [30].

Among the various areas where the public authorities can intervene -legal, fiscal, market access [64] — consumer protection is of particular importance, and within this area, privacy stands out [26], [30]. In fact there is some evidence of the positive effect of a political-legal framework for privacy on the development of business activity on the Internet ([24], [47], [56], among others).

This is because the Internet environment offers unprecedented opportunities for the invasion of privacy: it is easier to obtain information about individuals, combine it and integrate it with information obtained from conventional physical environments. Although it is possible to find out much more about consumers from these latter environments, access to this information can become too costly, can take too long or be too difficult to gather. Conscious of this, users value their privacy on the Internet very highly, and the control of the information obtained about them [27], and they are more liable to provide personal data and indeed to make purchases when there are mechanisms in place that control the personal information collected and what use is made of it [27], [63]. And since there is a positive relation between future purchase intention on the Internet and the probability of an effective purchase in the medium [9], we can plausibly expect that having a legal framework regulating privacy on the Internet will favor Internet transactions.

H2: The diffusion of broadband Internet connection technologies in the market and the establishment of a legal framework for online consumer protection positively influence the development of e-commerce.

\subsection{Factors relating to firm and its value proposition}

The previous section considered factors relating to the firm's competitive environment. It is also necessary to consider factors relating to the firm's internal environment. Including this second group of factors is habitual in holistic or integrative analyses of the adoption process of innovations such as e-commerce ([23], [33], among others), and helps explain why some firms opt to initiate e-commerce activities while others prefer to stick to conventional marketing formats.

One aspect relating to the firm's internal environment that authors have considered to be particularly important in the decision to adopt e-commerce is their marketing or business strategy. Indeed, the literature on e-commerce provides some evidence about the influence of the firm's strategy on the adoption and development of this marketing channel [67].

But the particular characteristics of the Internet raise the question of whether the company strategies advocated in the past few decades (differentiation of the value proposition, satisfying the customer by giving greater value, orientation towards the relationship, etc.) are appropriate on the Internet, and consequently whether such strategies favor the development of e-commerce or not.

These doubts about the use of such strategies on the Internet are due to the fact that online consumers have greater access to information about the commercial offer [5] and increased capacity to intervene directly in the shaping of a value proposition adapted to their specific preferences [48].

Some studies in the field of consumer behavior (e.g., [25], [49], [52]) have stressed the Internet's potential to enhance consumer empowerment. Moreover, a number of renowned authors (e.g. Alba et al. [1]) have related online consumers' greater empowerment with a supposed greater efficiency of electronic markets. The explanation for this would be that online consumers, who have a greater capacity for communicating with firms and other consumers, for 
identifying the best products to satisfy their needs, for evaluating their different purchase options, and for intervening in the design of the value proposition, would be more able to adopt efficient purchase decisions (i.e., acquiring the desired product more cheaply) [54]. This way of behaving would provoke an intense competition among the firms, fundamentally on the basis of price [5], [10].

Unlike in conventional environments, on the Internet there are intermediaries (the so-called shopbots) that provide access to information about the prices and products of a relatively large number of competing vendors, meaning that the cost (in time and effort) of searching for products is lower than is usual in traditional shopping [10], [57]. Information asymmetries between buyers and vendors conceivably decline with these purchasing agents, so that consumers seize more power in the exchange process.

All this has led to the prediction that as consumers become more skilled in the search for product information and use the Internet to enhance their empowerment, marketing communications, product differentiation and brand image, among other marketing tools, will lose their importance in the creation of signals of product characteristics, quality or suitability [68]. According to this argument, brands will lose their importance as guarantees of product quality, being replaced by information about the product, and the consumers will be able to identify which vendors provide the lowest prices for products of similar characteristics. Ultimately, greater price competition between companies can be expected, leading to a situation of perfect competition [1], [6].

However, the studies carried out have not provided definitive evidence about online price policies, partly due to the difficulty of generalizing from small samples [58]. Some research has found that the prices of certain products are higher on the Internet (e.g., [4], [13], [69]), but other work has found exactly the reverse ([10], [14], [35], [72], among others). In contrast, there does appear to be some agreement that price dispersion on the Internet is very high ([4], [7], [13], [14], [29], [35]), and even equivalent to that found in conventional environments, and also that there is a strong concentration of the supply, which means for example that retailers with the lowest prices do not obtain the highest sales [10].

We should consider a number of arguments that question the idea that e-commerce development is related to a greater emphasis on marketing and business strategies that involve price reductions:

- The diffusion of shopbots for product search and comparison is limited. Some consumers do not use the services of these intermediaries to search for and compare products, either because there are no shopbots available for the product-market they are interested in, or because they are relatively inexperienced users of the Internet (so they do not know that these systems exist, or how they work), or because they wish to invest the least time possible in their online purchases [68]. But in addition, some vendors prevent their products and prices from being considered by these purchasing agents [29], [57]

- Shopbots do not provide precise enough information about prices. In order to make accurate comparisons, consumers not only need to know the sales price of the product, which the shopbots provide, but also the transport charges, taxes and other costs involved in online purchasing [34].

- $\quad$ The information about product characteristics provided by the shopbots is beginning to become excessive. As the number of online businesses grows, so does the information these shopbots provide in their search results. Faced by such an excess of information consumers tend to take "shortcuts" or make heuristic evaluations [62]. These shortcuts take the form of purchasing in known and trusted sites, even if their prices are higher.

- $\quad$ Some firms use shopbots to reduce the effectiveness of consumer searches. They diffuse exceptionally low prices for a small number of their products to these intermediaries to encourage traffic to their virtual store, where the majority of their products are relatively more expensive [57].

Although shopbots put significant pressure on firms' margins [57], firms will conceivably keep developing strategies to mitigate the competitive pressure. These will include product differentiation, brand awareness and reputation [46], [59], [70]), segmentation practices and price discrimination [14], and so on.

Although the price is an important element in the design of the value proposition, other elements may also be important for online firms [17], [36], [39], [63]: product information, website design, customer service, reliability and speed of delivery, brand image, facilities for making orders, loyalty programs, personalization of the communication, switching costs, and so on. Researchers have found some evidence that an important segment of online consumers do not search actively in competing sites before making their purchase decisions (e.g., [16]), and that consumers are no more sensitive to prices online than they are in conventional environments (e.g., [17], [31], [60]). Moreover, convenience has been identified as one of the most important benefits sought by online consumers [12]. Online businesses that can exploit the benefits of convenience provide more satisfaction to consumers seeking to save time and effort in their purchases, or those who tend to purchase in reputed retailers and acquire recognized brands. 
Thus, it seems plausible to expect that firms will define online strategies to prevent prices from being pushed downwards and the market from heading toward perfect competition. Furthermore, this situation could be heightened as the sales attributable to e-commerce grow. This is because while e-commerce has a limited market, firms that adopt differentiation strategies in conventional environments would probably be more ready to sell their products on the Internet more cheaply, in the expectation that they will eventually be reaching a sufficiently attractive number of customers [50]. But as e-commerce expands, companies will probably opt for the same competitive strategy on the Internet as they adopt in conventional environments [50], [71]. Consequently, the third hypothesis is as follows:

H3: An emphasis on marketing elements that differentiate the value proposition and provide the consumer with greater value (to the detriment of price-related strategies) is positively associated with the development of ecommerce.

Finally, we should consider that vendors' adoption of systems making communications and transactions on the Internet more secure may significantly influence the results of their commercial activity in this medium. This is because in spite of advances in security mechanisms (cryptography, authentication) consumers may be reluctant to use the Internet to carry out secure transactions. Negative perceptions about security may still represent an important brake on online purchases [8], [37], [42], [63].

It seems then that winning the consumer's confidence is an important objective for companies operating on the Internet, since e-commerce purchases not only involve the traditional risks of direct sales (examination of goods before purchase, deferred delivery, returns, etc.), but additional risks as well, such as the fraudulent use of credit cards [32], which are only partially solved by means of bricks-and-mortar strategies [28]. Thus, incorporating various technological components into the process (security protocols, guarantee seals from brands such as Visa or VeriSign, high-quality website design technology, etc.) may help generate confidence in Internet retailers [51], which will ultimately favor e-commerce sales.

H4: Designing an online value proposition perceived as "secure" positively influences the development of ecommerce.

\section{Methodology}

We should point out that the data used refer to a specific geographical area-the Spanish market. Whatever the market, collecting data about the e-commerce phenomenon is not without its difficulties. There are few measurements made, and the ones that are often focus more on access and connectivity than on the use that is made of the Internet in the commercial sphere and business [66]. This obliged us, as we describe below, to resort to various sources that employ different methodologies to obtain the data for the variables considered in our model.

First, we used the sales turnover from B2C e-commerce in Spain (expressed in millions of euros) as indicator of the dependent variable - the adoption and development of e-commerce. Following OECD recommendations, this indicator represents the sum of Spanish consumers' transactions on the Internet, regardless of the medium employed subsequently for the distribution and payment of the products purchased.

The data on this indicator were obtained from the Study of B2C E-commerce, a representative survey of the Spanish population over 14 years of age elaborated annually from 1996 by the AECEM (the Spanish Association of Ecommerce) and the Red.es Observatory (the public firm of the Spanish Government that promotes the development of the Information Society). The survey is based on computer-aided telephone interviews (Bellview-CATI system) of a sample of the population selected at random from telephone lists. Of the 5,012 respondents in the latest survey, 497 made purchases on the Internet. From this group we obtained the data relating to purchase behavior.

Second, to measure the size of the potential market represented by the Internet we used the number of Internet users in Spain (in thousands of users), again with data from 1996 to 2003. An Internet user is understood to be a person over 14 years of age who accesses the medium at least once a month.

The data were obtained from the General Framework of the Media in Spain, elaborated by the Spanish Association for Research into the Communications Media (AIMC) on the basis of the General Media Study (EGM). The EGM is a representative survey of the Spanish population over 14 years of age enquiring about the general audience of the communications media. It is carried out three times a year, and the complete survey is based on approximately 43,000 personal interviews.

Third, to measure the technological factor (diffusion of broadband) and legal factor (legal framework of consumer protection on the Internet) of the competitive environment of e-commerce, we used a dichotomous variable that equals 0 for the period between 1996 and 2001, and 1 from 2002 onwards. These values can be expected to capture the structural change occurring from 2002 caused by the take-off of ADSL among private users -after the Spanish Telecommunications Market Commission authorized the dominant operator to begin operating as a direct service provider- and the diffusion of the draft of the first bill designed to regulate commercial activities on the Internet, Law 34/2002, 11th July, known as the Law of Information Society Services and Electronic Commerce. 
Fourth, as indicator of the relative importance of differentiation strategies and consumer relationships compared to price leadership strategies, we used the price of one of the best-selling products on the Internet - the computer. For this, we took data provided annually by the European Information Technology Observatory on the prices (in euros) of the best performing computer on the market at any given time in Europe.

Table 1: Most bought products on Internet (\%) (2003)

\begin{tabular}{|lr|}
\hline Tickets (plane, train, boat, bus...) & 12.2 \\
Computers, components, and peripheries & 10.2 \\
Leisure, free time, and tickets for shows & 10.1 \\
Books and magazines & 9.5 \\
Accommodation (hotel, rural hotel...) & 7.7 \\
\hline \multicolumn{2}{|c}{ Source: AIMC. }
\end{tabular}

Finally, for the security factor in firms' value proposition on the Internet, we took as indicator the number of servers with the ".es" domain - the country code for Spain — that use security protocols per 1,000 users. To measure this we used the data elaborated for Spain by the services firm Netcraft. This firm carries out an automatic review of the secure servers on the Internet every month.

Since the time-series data obtained from these sources differed in terms of periodicity, and the phenomenon of interest is very recent, which implies that the series with annual data are very short, we considered it necessary to carry out a process of interpolation. We used this process to convert the initial data into series of 85 periods, each of which referred to an approximation of the monthly observation of the variables (from December 1996 to December 2003).

To derive the series, we carried out an interpolation by third-order cubic splines [15], which allows us to approximate functions of which we only know some values. By means of this numerical analysis we built (and united) pieces of third-order polynomials that link together with C1-continuity, such that the second derivative of each polynomial is zero at the ends. In this way we ensured that the curve (approximation) obtained passes through each of the initial points with which it was created.

\section{Results}

\subsection{Evolution of Electronic Commerce Adoption}

Looking at the evolution in the volume of e-commerce in the market analyzed from 1996 to 2003 we should highlight the strong growth experienced in recent years. As Figure 1 shows, from the year 2001 onwards there is a clear acceleration in the growth. From this particular year a number of important events occurred that may have had an effect on this, such as the development of broadband and with it the appearance of flat-rate charges for Internet access, and the preparation of the Law of Information Society Services and Electronic Commerce. However, the concave form that the curve takes on from the year 2002 onwards suggests a possible slowing of the growth.

On the other hand, we have analyzed the evolution of one of the factors considered decisive in explaining ecommerce-the size of the potential market, measured by the number of Internet users. Unlike what happens with the e-commerce sales volume, the evolution of this variable does not appear to have undergone significant changes of trend.

Analyzing the direct relation between the variables sales volume and number of users through the approximation of the average amount spent per user we see the phenomena mentioned more clearly. On the one hand, the concavity of the curve for the evolution of e-commerce, which appears to indicate a slowing of the growth and a change of tendency from 2001. In contrast, throughout 2003 the growth in average spending was much more modest, with average spending reaching $€ 156.30$ at the end of the year.

The coefficient of correlation between the two variables is 0.897 . Hence, if we want to explain the evolution of ecommerce through a simple linear regression, then the coefficient of determination equals $(0.897)^{2}=0.805$. This implies that $19.5 \%$ of the variation of the sales volume from e-commerce is not explained by the Internet users. Therefore, additional factors must be considered to explain the evolution of e-commerce more precisely. This is the task of the next section. 


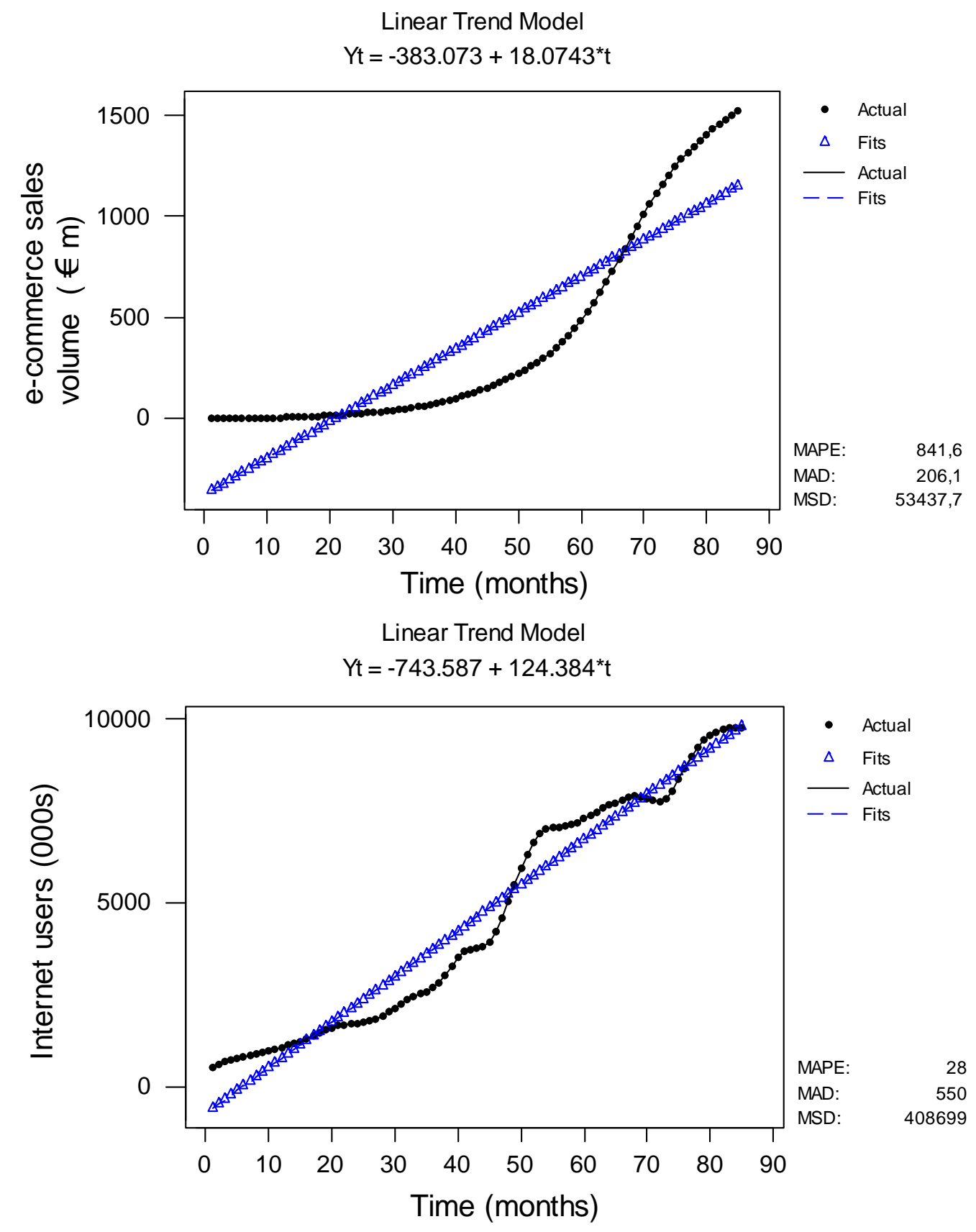

Figure 1: Evolution of e-commerce sales volume and Internet users and analysis of trend

\subsection{Estimation of Explanatory Model}

As we have been able to confirm, the importance of the evolution of the Internet users in explaining the evolution of e-commerce is very high. In this respect, if we carry out a first study of the dependence of these two variables, taking into account the structural change mentioned above, we lay the foundations for building the explanatory model designed in the previous section.

From a first analysis of the linear regression between the two variables (see Table 2), in which we introduce a dummy variable to measure the technological and legal changes occurring in 2001, we find that practically $92.5 \%$ of the variability in the sales volume is explained by the evolution in the number of users. The coefficient accompanying the variable is significantly different from zero $(p=0.000)$ and positive in sign, so we can consider the first hypothesis of our theoretical model $(\mathrm{H} 1)$ confirmed.

Likewise, we note the presence of a structural change from the year 2001, since the coefficient corresponding to the dummy variable is significantly different from zero $(p=0.000)$. Thus, we can also confirm the second hypothesis of the 
model $(\mathrm{H} 2)$. As a whole, the development of the technological and legal framework positively influences the growth of e-commerce.

Table 2: Regression analysis with sales volume and Internet users

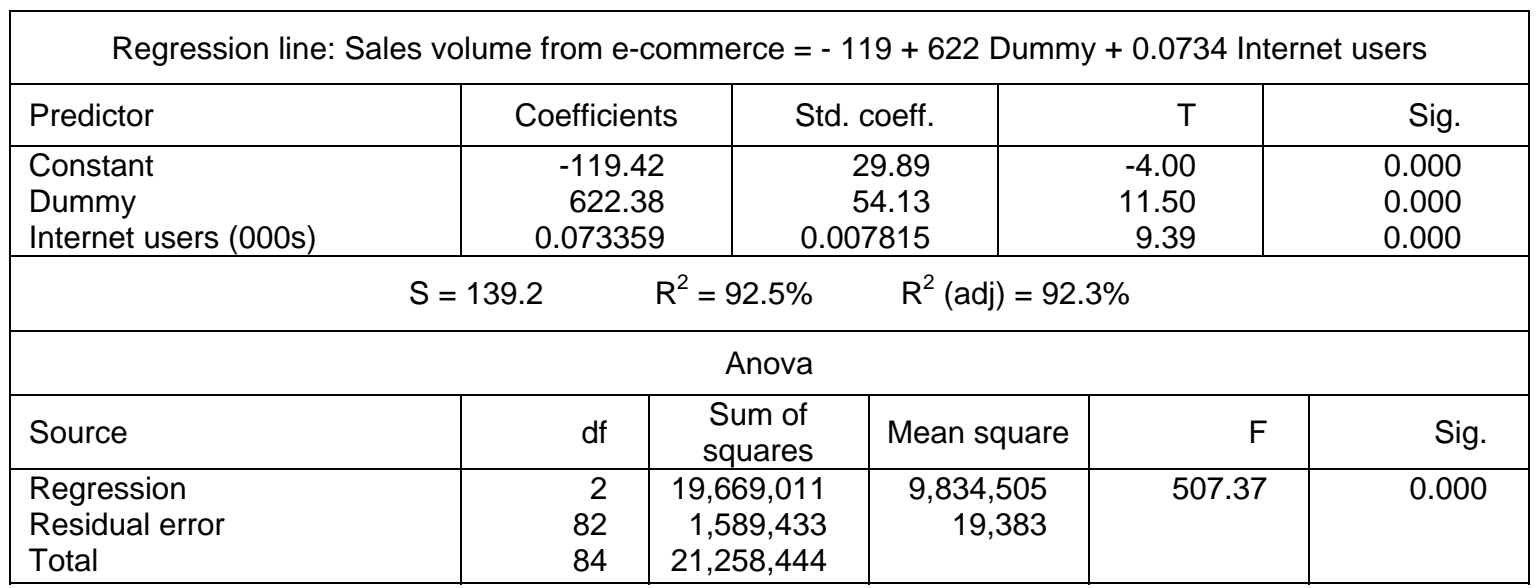

We then ran a new multiple regression analysis considering not only the determinants considered above, but also the rest of the variables identified in the literature review (see Table 3). From the results obtained we should mention that the explanation of the total variability of the dependent variable (e-commerce sales volume) improves with the incorporation of the new variables into the model. Hence the $\mathrm{R}^{2}$ goes from $92.5 \%$ to $95.9 \%$. Likewise, we observe that the model is significant as a whole (the F-value of the analysis of variance is high, with a p-value equal to zero), and the variables considered have coefficients significantly different from zero (with $p$-values equal to zero). This means that their presence is statistically justified in the explanatory model.

With this analysis, hypotheses $\mathrm{H} 1$ and $\mathrm{H} 2$ continue to be valid, but at the same time we confirm the validity of the two remaining hypotheses, $\mathrm{H} 3$ and $\mathrm{H} 4$. Thus, the significance of the coefficient associated with the variable "Price of computers" $(p=0.000)$ and its positive sign allows us to validate Hypothesis H3. This positive effect on the evolution of e-commerce shows that the possession of computers is not a significant barrier to accessing the Internet, in contrast to the findings of previous modelizations in the same area [43], [55]. The positive relation between the price of this product (one of the most exchanged on the Internet) and the sales turnover attributable to e-commerce appears to be indicating that demand on the Internet is inelastic, and that other marketing tools (brand image, quality, customer service, etc.) may be more important to the consumers accessing this medium.

On the other hand, and with regard to Hypothesis $\mathrm{H} 4$, we find that the variable "Secure servers" is also significant in the model (the regression coefficient associated with this variable is significantly different from zero, with $p=0.000$ ). Its effect on the evolution of e-commerce has, moreover, a positive sign, since its growth positively affects the volume of e-commerce.

Table 3: Regression analysis with sales volume and explanatory factors

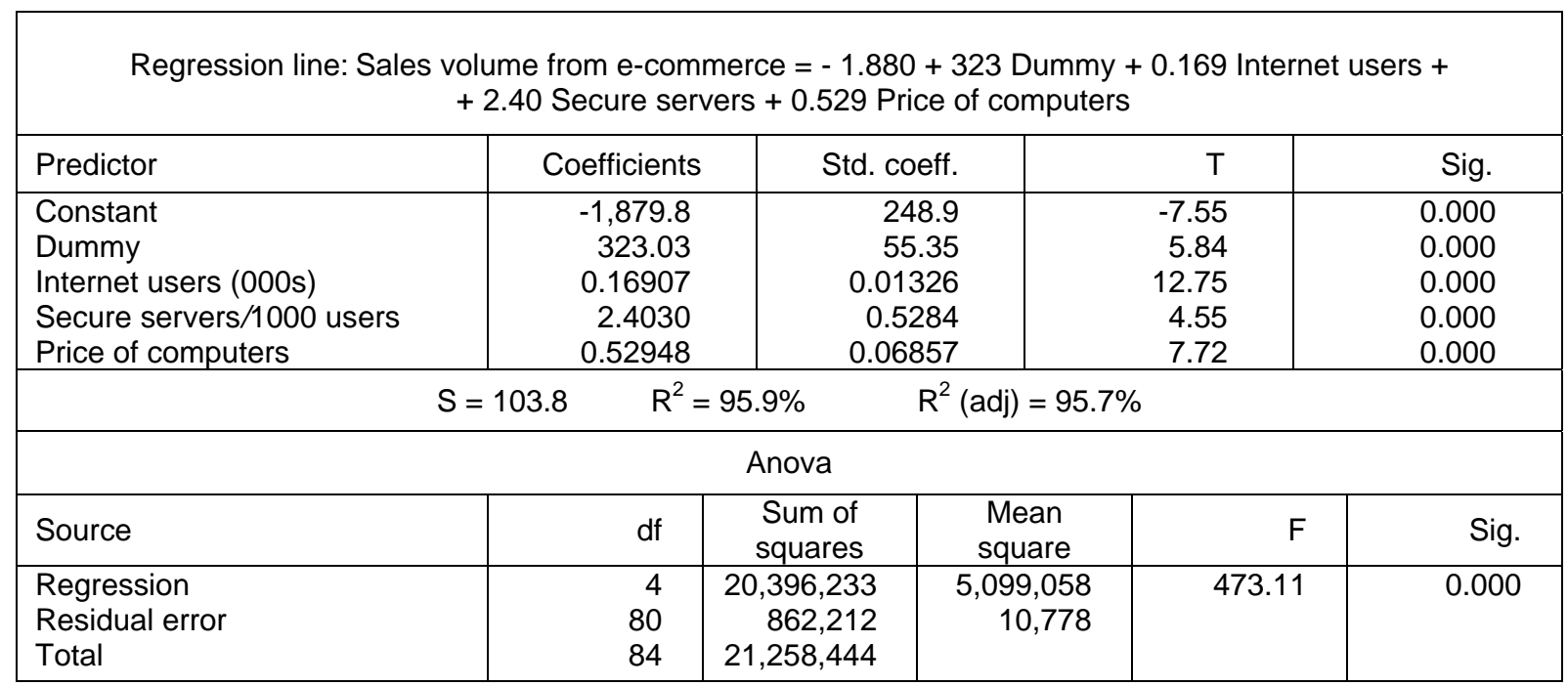




\section{Final discussion and concluding remarks}

This current work defines a theoretical model to explain the evolution in B2C e-commerce adoption and development, which considers different types of determinant of this phenomenon. We also evaluate the validity of the model obtained for a particular context - the Spanish market- using a database from varying sources (public and private) that are representative of the whole Spanish economy during the period 1996-2003.

The first of the determinants considered - the potential market on the Internet- reflects the influence of a commercial factor from the Internet firms' competitive environment. According to the results obtained here for the Spanish case, this determinant has a decisive importance in the development of e-commerce, far exceeding that of the remaining determinants examined.

We appear to have reached a critical mass of users, making up a market with a sufficiently attractive size to firms, thereby ensuring their increasing interest in e-commerce. This would explain why, at the same time as the community of users has grown linearly, the sales volume generated by e-commerce has seen a clearly exponential growth after the number of users passed a particular threshold (which in the market analyzed here would be at around 7 million users).

In the light of these results, we deduce that future increases in the size of the Internet user community could result in a proportionately higher growth in the sales volume attributable to e-commerce (the elasticity of this variable in the analytical model is 1.09).

However, we also find that the size of the potential market and its evolution are not the only type of factor influencing e-commerce adoption and development. Also relevant are other determinants concerning the companies' technological-legal environment, their commercial offer and the technological infrastructure they have available for Internet services.

Regarding the technological and legal environment, we might mention two elements that condition the evolution of ecommerce: the adoption of broadband technology and the definition of a legal framework of consumer protection on the Internet.

From our findings we can deduce that in developed countries such as Spain, in which Internet penetration rates among the population are beginning to be high (over $50 \%$ of the population), the diffusion of broadband plays a significant role. This type of technology facilitates users' access to advanced systems of commercial communication, personalized attention, and so on, making the Internet a more attractive environment for commercial transactions. Its importance is in line with the initiatives of various governments, such as those of the European Union, which are promoting the diffusion of broadband in order to improve the competitiveness and dynamism of their economies [20]. Equally, the establishment of a legal framework on the question of privacy, although it cannot provide complete protection for consumers on the Internet, is shown to be necessary for the development of e-commerce.

The next determinant contemplated (differentiation strategy versus price leadership strategy) reflects the commercial characteristics of the business offer on the Internet. The fact that the price of computers (one of the most sold products on the Internet) has a significantly positive effect when explaining the development of e-commerce according to the analytical model proposed here leads us to deduce, on the one hand, that the computer is no longer an indicator of the barriers to access to the Internet, at least in developed countries that have achieved a critical mass of users.

On the other hand, the positive relation between the price level on the Internet and the sales volume due to ecommerce shows that electronic markets do not lead to a generalized reduction in prices. Instead, this positive relation indicates the importance of the traditional elements in the definition of a differentiated marketing strategy providing greater value to the consumers, and contributing to building closer relationships with them.

The last factor considered (security in the offer on the Internet), relating to technological aspects of the value proposition, has also been shown to be significant in explaining e-commerce. Once again, consumers' confidence in the security of the communications and commercial exchange mechanisms provided by the companies is shown to encourage purchasing on the Internet.

Finally, we should mention that the object of this study is a dynamic phenomenon that is currently in a relatively immature situation. Thus, the determinants identified here as relevant and their effects on the development of ecommerce could change in the future. With the growing adoption of e-commerce by new strata in the population not corresponding to the profile of the early Internet users (urban population, with a university education, income levels above the population average, and with computer equipment in the home) [53], some of the behaviors observed here (such as the lower price sensitivity, for example) could possibly change. Thus, it is important to continue testing the model with data from later time periods, either to confirm its validity or to find ways of perfecting it. 


\section{References}

[1] J. Alba, J. Lynch, B. Weitz, C. Janiszewski, R. Lutz, A. Sawyer and S. Wood, Interactive home shopping: consumer, retailer, and manufacturer incentives to participate in electronic marketplaces, Journal of marketing, vol. 61, no. 3, pp. 38-53, 1997.

[2] A. Ansari and C. F. Mela, E-customization, Journal of Marketing Research, vol. 40, no. 2, pp. 131-145, 2003.

[3] D. C. Arnott and S. Bridgewater, Internet, interaction and implications for marketing, Marketing Intelligence \& Planning, vol. 20, no 2, pp. 86-95, 2002.

[4] J. P. Bailey, Electronic commerce: prices and consumer issues for three products: books, compact discs and software, OECD, Technical Report OECD/GD 98 4, 1998.

[5] J. Y. Bakos, Reducing buyer search costs: implications for electronic marketplaces, Management Science, vol. 43, no. 12, pp. 1676-1692, 1997.

[6] Y. J. Bakos, The emerging role of electronic marketplaces on the Internet, Communication of the ACM, vol. 41, no. 8, pp. 35-42, 1998

[7] M. R. Baye, J. Morgan and P. Scholten, Price dispersion in the small and in the large: evidence from an Internet price comparison site, The Journal of Industrial Economics, vol. 52, no. 4, pp. 463-496, 2004.

[8] A. Bhatnagar, S. Misra and H. R. Rao, On risk, convenience, and Internet shopping behaviour, Communications of the ACM, vol. 43, no. 11, pp. 98-105, 2000.

[9] M. Brown, N. Pope and K. Voges, Buying or browsing? An exploration of shopping orientations and online purchase intention, European Journal of Marketing, vol. 37, no. 11-12, pp. 1.666-1.684, 2003.

[10] E. Brynjolfsson and M. D. Smith, Frictionless commerce? A comparison on Internet and conventional retailers, Management Science, vol. 46, no. 4, pp. 563-585, 2000.

[11] R. Cagliano, F. Caniato and G. Spina, E-business strategy. How companies are shaping their supply chain through the Internet, International Journal of Operations \& Production Management, vol. 23, no. 10, pp. 11421162, 2003.

[12] K. -P. Chiang and R. R. Dholakia, Factors driving consumer intention to shop online: an empirical investigation, Journal of Consumer Psychology, vol. 13, no. 1-2, pp. 177-183, 2003.

[13] K. Clay, R. Krishnan, E. Wolff and D. Fernandes, Retail strategies on the web: price and non-price competition in the online book industry, Journal of Industrial Economics, vol. 50, no. 3, pp. 351-367, 2002.

[14] E. K. Clemons, I. H. Hann and L. M. Hitt, Price dispersion and differentiation in online travel: an empirical investigation, Management Science, vol. 48, no. 4, pp. 534-549, 2002.

[15] G. Dahlquist and A. Björk, Numerical methods. Englewood Cliffs, New Jersey: Prentice-Hall, 1974.

[16] C. A. Deck and B. J. Wilson, Tracking customer search to price discriminate, Economic Inquiry, vol. 44, no. 2, pp. 280-295, 2006.

[17] A. Degeratu, A. Rangaswamy and J. Wu, Consumer choice behavior in online and traditional supermarkets: the effects of brand name, price and other search attributes marketing science and the Internet, International Journal of Research in Marketing, vol. 17, no. 1, pp. 55-78, 2000.

[18] U. M. Dholakia and L. L. Rego, What makes commercial Web pages popular? An empirical investigation of Web page effectiveness, European Journal of Marketing, vol. 32, no. 7-8, pp. 724-736, 1998.

[19] A. Dutta, The physical infrastructure for electronic commerce in developing nations: historical trends and the impact of privatization, International Journal of Electronic Commerce, vol. 2, no. 1, pp. 61-83, 1997.

[20] European Commission 2002. eEurope 2005: an information society for all.

[21] I. Fillis, U. Johannson and B. Wagner, Factors impacting on e-business adoption and development in the smaller firm, International Journal of Entrepreneurial Behaviour \& Research, vol. 10, no. 3, pp. 178-191, 2004.

[22] J. Fisher and G. Harindranath, Regulation as a barrier to electronic commerce in Europe: the case of the European fund management industry, European Journal of Information Systems, vol. 13, no. 4, pp. 260-272, 2004.

[23] J. L. Gibbs and K. L. Kraemer, A cross-country investigation of the determinants of scope of e-commerce use: an institutional approach, Electronic Markets, vol. 14, no. 2, pp. 124-137, 2004.

[24] T. R. Graeff and S. Harmon, Collecting and using personal data: consumers' awareness and concerns, Journal of Consumer Marketing, vol. 19, no. 4, pp. 302-318, 2002.

[25] T. Harrison, K. Waite and Hunter, G.L., The Internet, information and empowerment, European Journal of Marketing, vol. 40, no. 9-10, pp. 972-993, 2006.

[26] D. L. Hoffman and T. P. Novak, Advertising and pricing models for the Web, in Internet publishing and beyond: the economics of digital information and intellectual property (D. Hurley, B. Kahin and H. Varian, Eds.). Cambridge, MA: MIT Press, 2000, pp. 45-61.

[27] D. L. Hoffman, T. P. Novak and M. Peralta, Information privacy in the marketspace: implications for the commercial uses of anonymity on the Web, The Information Society, vol. 15, no. 2, pp. 129-139, 1999.

[28] E. K. R. E. Huizingh, Towards successful e-business strategies: a hierarchy of three management models, Journal of Marketing Management, vol. 18, no. 7-8, pp. 721-747, 2002.

[29] G. Iyer and A. Pazgal, Internet shopping agents: virtual co-location and competition, Marketing Science, vol. 22, no. 1, pp. 85-106, 2003.

[30] R. Javalgi and R. Ramsey, Strategic issues of e-commerce as an alternative global distributions system, International Marketing Review, vol. 18, no. 4, pp. 376-391, 2001.

[31] T. Jensen, J. Kees, S. Burton and F. L. Turnipseed, Advertised reference prices in an Internet environment: effects on consumer price perceptions and channel search intentions, Journal of Interactive Marketing, vol. 17, no. 2, pp. 20-33, 2003 
[32] A. K. Kau, Y. E. Tang and S. Ghose, Typology of online shoppers, Journal of Consumer Marketing, vol. 20, no. 2, pp. 139-156, 2003.

[33] C. Kim and R. D. Galliers, Toward a diffusion model for Internet systems, Internet Research, vol. 14, no. 2, pp. 155-166, 2004.

[34] M. Kung, K. B. Monroe and J. L. Cosx, Pricing on the Internet, Journal of Product \& Brand Management, vol. 11, no. 5, pp. 274-287, 2002.

[35] Z. Lee and S. Gosain, A longitudinal price comparison for music CDs in electronic and brick-and-mortar markets: pricing strategies in emergent electronic commerce, Journal of Business Strategies, vol. 19, no. 1, pp. 55-71, 2002.

[36] L. Lee-Kelley, D. Gilbert and R. Mannicom, How e-CRM can enhance customer loyalty, Marketing Intelligence \& Planning, vol. 21, no. 4, pp. 239-248, 2003.

[37] Y. Liebermann and S. Stashevsky, Perceived risks as barriers to Internet and e-commerce usage, Qualitative Market Research, vol. 5, no. 2, pp. 291-300, 2002.

[38] G. L. Lohse and P. Spiller (1999, December). Internet retail store design: how the user interface influences traffic and sales, Journal of Computer Mediated Communication [Online]. vol. 5, no. 2. Available: http://jicmc.indiana.edu/vol5/issue2.

[39] J. G. Lynch and D. Ariely, Wine online: search costs affect competition on price, quality, and distribution, Marketing Science, vol. 19, no. 1, pp. 83-103, 2000.

[40] N. Mandel and E. J. Johnson, When web pages influence choice: effects of visual primes on experts and novices, Journal of Consumer Research, vol. 29, no. 2, pp. 235-245, 2002.

[41] P. McGowan and M. G. Durkin, Toward an understanding of Internet adoption at the marketing/entrepreneurship interface, Journal of Marketing Management, vol. 18, no. 3-4, pp. 361-377, 2002.

[42] D. H. McKnight, V. Choudhury and C. Kacmar, The impact of initial consumer trust on intentions to transact with a web site: a trust-building model, The Journal of Strategic Information Systems, vol. 11, no. 3-4, pp. 297-323, 2002.

[43] A. Meseguer, I. Rodríguez-Ardura and J. Vilaseca, Situación y perspectivas del comercio electrónico en España: un análisis a través del volumen del negocio electrónico, Esic Market, vol. 114, pp. 77-107, 2003.

[44] A. Molla and P.S. Licker, eCommerce adoption in developing countries: a model and instrument, Information \& Management, vol. 42, no. 6, pp. 877-899, 2005

[45] R. M. O'Keefe, G. O'Connor and K. Hsiang-Jui, Early adopters of the web as a retail medium: small company winners and losers, European Journal of Marketing, vol. 32, no. 7-8, pp. 629-643, 1998.

[46] X. Pan, B. T. Ratchford and V. Shankar, Can price dispersion in online markets be explained by differences in etailer service quality?, Journal of the Academy of Marketing Science, vol. 30, no. 4, pp. 433-445, 2002.

[47] J. Phelps, G. Nowak and E. Ferrell, Privacy concerns and consumer willingness to provide personal information, Journal of Public Policy \& Marketing, vol. 19, no. 1, pp. 27-41, 2000.

[48] G. D. Pires, J. Stanton and P. Rita, The Internet, consumer empowerment and marketing strategies, European Journal of Marketing, vol. 40, no. 9-10, pp. 936-949, 2006.

[49] L. F. Pitt, P. R. Berthon, T. R. Watson and G. Zinkhan, The Internet and the birth of real consumer power, Business Horizons, vol. 45, no. 6, pp. 7-14, 2002.

[50] M. A. Porter, Strategy and the Internet, Harvard Business Review, vol. 79, no. 3, pp. 62-78, 2001.

[51] J. Reynolds, eCommerce: a critical review, International Journal of Retail \& Distribution Management, vol. 28, no. 10, pp. 417-444, 2000

[52] B. Rezabakhsh, D. Bornemann, U. Hansen and U. Schrader, Consumer power: a comparison of the old economy and the Internet economy, Journal of Consumer Policy, vol. 29, no. 1, pp. 3-36, 2006.

[53] I. Rodríguez-Ardura, Marketing.com y comercio electrónico en la sociedad de la información, 3rd ed. Madrid: Pirámide and ESIC, 2008.

[54] I. Rodríguez-Ardura and F. J. Martínez-López, Playing cat and mouse: consumer empowerment and marketing interaction on the Internet, International Journal of Business Environment, vol. 2, no. 2, pp. 201-214, 2008.

[55] I. Rodríguez-Ardura, A. Meseguer, E. Hormigo and G. Ryan, El futuro de la venta telemática en España a través de la World Wide Web: un modelo estructural, in Proceedings XI Encuentro de Profesores Universitarios de Marketing. Madrid: ESIC Editorial, 1999, pp. 315-331.

[56] K. B. Sheehan and M. G. Hoy, Dimensions of privacy concern among online consumers, Journal of Public Policy \& Marketing, vol. 19, no. 1, pp. 62-73, 2000.

[57] M. D. Smith, The impact of shopbots on electronic markets, Journal of the Academy of Marketing Science, vol. 30, no. 4, pp. 446-454, 2002.

[58] M. D. Smith, J. P. Bailey and E. Brynjolfsson, Understanding digital markets: review and assessment, in Understanding the digital economy: data, tools, and research (E. Brynjolfsson y B. Kahin, Eds.). Cambridge, MA: MIT Press, 2000, pp. 99-136.

[59] M. D. Smith and E. Brynjolfsson, Consumer decision-making at an Internet shopbot: brand still matters, Journal of Industrial Economics, vol. 49, no. 4, pp. 541-558, 2001.

[60] F. Sotgiu and F. Ancarani, The drivers of e-tailers' price levels, International Review of Retail, Distribution and Consumer Research, vol. 15, no. 1, pp. 75-89, 2005

[61] A. Stewart, R. Mulye, K. R. Deans and D. Palihawadana, E-marketing in perspective: a three country comparison of business use of the Internet, Marketing Intelligence \& Planning, vol. 20, no. 4, pp. 243-251, 2002.

[62] R. Suri, M. Long and K. B. Monroe, The impact of the Internet and consumer motivation on evaluation of prices, Journal of Business Research, vol. 56, no. 5, pp. 379-390, 2003. 
[63] V. Swaminathan, E. Lepkowska-White and B. P. Rao, Browser or buyers in cyberspace? (1999, December). An investigation of factors influencing electronic exchange, Journal of Computer Mediated Communication [Online]. vol. 5, no. 2. Available: http://jcmc.indiana.edu/vol5/issue2.

[64] The White House. (1997, July). A framework for global electronic commerce, Washington, DC [Online]. Available: http://www.technology.gov/digeconomy/framewrk.htm.

[65] M. L. To and E. W. T. Ngai, Predicting the organisational adoption of B2C e-commerce: an empirical study, Industrial Management \& Data Systems, vol. 106, no. 8, pp. 1133-1147, 2006.

[66] J. Vilaseca, J. Torrent, C. Cabañero, D. Castillo, R. Colomé, Á. Díaz, P. Ficapal, A. I. Jiménez, J. Lladós, M. J. Martínez, A. Meseguer, D. Plana and I. Rodríguez-Ardura, ICTs and transformations in Catalan companies. Barcelona: Universitat Oberta de Catalunya and Generalitat de Catalunya, 2004.

[67] J. Vilaseca, J. Torrent, A. Meseguer and I. Rodríguez-Ardura, An integrated model of adoption and development of e-commerce in companies, International Advances in Economic Research, vol. 13, no. 2, pp. 222-241, 2007.

[68] M. R. Ward and M. J. Lee, Internet shopping, consumer search and product branding, Journal of Product \& Brand Management, vol. 9, no. 1, pp. 6-20, 2000.

[69] X. Xing, F. -F. Tang and Z. L. Yang, Pricing dynamics in the online consumer electronics market, Journal of Product and Brand Management, vol. 13, no. 6, pp. 429-441, 2004.

[70] X. Xing, Z. Yang, and F. -F. Tang, A comparison of time-varying online price and price dispersion between multichannel and dotcom DVD retailers, Journal of Interactive Marketing, vol. 20, no. 2, pp. 3-20, 2006.

[71] F. Zettelmeyer, Expanding to the Internet: pricing and communications strategies when firms compete on multiple channels, Journal of Marketing Research, vol. 37, no. 3, pp. 292-308, 2000.

[72] F. Zettelmeyer, F. S. Morton and J. Silva-Risso, How the Internet lowers prices: evidence from matched survey and automobile transaction data, Journal of Marketing Research, vol. 43, no. 2, pp. 168-181, 2006. 